\title{
The Effect of Fluids Intake Counseling with Poster Media to Interdialytic Weight Gain (IDWG)
}

\author{
Erna Dwi Wahyuni \\ Faculty of Nursing Universitas Airlangga \\ Surabaya, Indonesia \\ Erna-d-w@fkp.unair.ac.id \\ Rizki Eko Wicaksono \\ Faculty of Nursing Universitas Airlangga \\ Surabaya, Indonesia
}

\author{
Lailatun Ni'mah \\ Faculty of Nursing Universitas Airlangga \\ Surabaya, Indonesia \\ lailatunnimah@fkp.unair.ac.id
}

\begin{abstract}
The Increasing of interdialytic weight gain was found among chronic kidney disease patients, 32\% patients still had IDWG amount above 3kgs in Hemodialysis Unit PHC Hospital. This study aimed to explain the effect of fluids intake counseling with poster media to interdialytic weight gain. The design of this study was quasi-experimental with 15 people of control group and 15 people of treatment group patients who were taken by using purposive sampling technique. Independent variable of this study was fluids intake counseling with poster media. Dependent variable was interdialytic weight gain patients. Data were taken by using questionnaire then analyzed by using statistical test, paired t-test and independent t-test. The result showed a significant effect of fluids intake counseling with poster media on interdialytic weight gain (IDWG) in the treatment group ( $p=$ 0.000 ), and not significant value in control group which was not given fluids intake counseling with poster media $(p=0.164)$. Statistical test independent $t$-test showed that there was difference between treatment group and control group in post implementation $(p=0.002)$. It can be concluded that fluids intake counseling with poster media influence interdialytic weight gain. This study suggests the nurses at Hemodialysis Unit in PHC Hospital to arrange a health education regularly related to fluids intake counseling with poster media and the further research can arrange new research relates to this study more specific such as the effect of motivation and knowledge to fluids intake.
\end{abstract}

Keyword: Chronic Kidney Disease, fluids intake, counseling, poster media, Interdialytic Weight Gain (IDWG)

\section{INTRODUCTION}

End Stage Renal Disease (ESDR) is a progressive impairment of renal function and irreversible kidney in the body's ability to maintain metabolism and fluid and electrolyte balance causing uremia (retention of urea and other nitrogen garbage in the blood) [1]. Chronic Kidney Disease (CKD) occurs when the kidneys no longer able to maintain the ideal environment for survival. Kidney damage is irreversible. The cause of CKD include infection, inflammation, vascular hypertensive, connective tissue disorders, hereditary congenital disorders, metabolic diseases, toxic nephropathy, and obstructive nephropathy [2]. Interdialytic Weight Gain (IDWG) is an easily measurable parameter in the dialysis unit, routinely assessed at the beginning of the dialysis session. Instability of IDWG often occurs in patients with CKD because of education is not maximally given.

CKD incidence increases from year to year. Patients with CKD in Indonesia in 2009 prevalence of $12.5 \%$ or 18 million adults affected by chronic kidney disease. Indonesia Health Profile Data in 2006, mentions kidney failure ranks sixth as the cause of death of the client being treated at hospitals across Indonesia 2.99\% [3]. Data East Java Health Office in 2010 mentions incidents of chronic renal failure in East Java 1-3 of 1.000 population. Preliminary study that has been conducted by researchers on December 6, 2016 found a total of clients undergoing regular hemodialysis twice a week in Portal Health Center (PHC) Hospital Surabaya were 125 patients, and 40 patients $(32 \%)$ of them still had IDWG above $3 \mathrm{~kg}$. IDWG enhancement is due to various factors from the patient's knowledge and behavior. Education has been given to CKD patients at PHC Hospital by using leaflets, but the effect was still not maximal. Other approaches need to be done, such as counseling by using poster media, but the effect of counseling using poster media to the reduction of IDWG still can not be explained clearly.

CKD treatments are divided into two stages, the conservative measures and dialysis, or a kidney transplant. Some studies show that success in carrying out the management of Chronic Renal Failure (CRF) is based on the elements of the diverse, including routine in undergoing hemodialysis, self-management clients, empowering clients and compliance clients in fluid restriction [4].

Restriction of fluid intake to clients with CRF is very important to note. Too much fluid intake can lead to fast weight gain (exceeding 5\%), edema, ronchi, wet lungs, eyelid swelling and shortness of breath caused by excessive fluid volume and uremic symptoms [1]. Oral fluid intake in clients with CRF should be monitored carefully. Some clients have difficulty in restricting fluid intake, but they do not get the proper understanding of the strategies that can help them in a fluid restriction, so the increase IDWG beyond normal limits may occur [5]. Reports IDWG prevalence increases 
significantly in some countries, by $9.7 \%-49.5 \%$ in the United States and 9.8\% - 70\% in Europe [6].

IDWG is an increase in fluid volume manifested by weight gain as an indicator to determine the amount of fluid intake during interdialitic periods and client compliance with fluid regulation in clients receiving hemodialysis therapy. IDWG value that can be tolerated is about 2 to 3 pounds or about 0.9 to 1.3 kilograms. IDWG can be caused by various factors both internal factors include age, gender, level of education, thirst, stress, self-efficacy, as well as external factors, namely the family and social support as well as the amount of fluid intake [7].

Behavior and knowledge greatly affect the success of the CKD management. Health education is one form of intervention that can be performed on the client CRF to provide and improve knowledge in improving health. In order to improve and promote public health, behavioral intervention is a strategic step in achieving the goals [8].

Health education provided to CKD patients not yet provides maximum impact to decline IDWG. According to research conducted by [9], from 222 CKD patients, $58.7 \%$ of them did not comply with the liquid restrictions, so it needs to get counseling and education regularly and continuously to change the behavior. Counseling methods can adapt to the needs of the patient. [8] states that the change in behavior of health education is influenced by many factors, including the material or message, educator or the person who did it, and aids are used to support health promotion process. In addition to counseling and fluid intake, there are several kinds of media tool that supports the process of health education such as TV, videos, posters, booklets, and others.

Poster is a medium in the form of paper containing information about the knowledge of writing and drawing. The advantages of this poster media is structured words, simple but easy to understand and be understood, lightweight and can be posted in strategic places. In contrast to the leaflet which can be lost at any time. Counseling about fluid intake using poster media is a platform for health workers to provide knowledge to the client. Clients gain additional knowledge about the disease (CKD) and appropriate fluid intake information for patients with CKD. Along with increasing knowledge of the client, will be able to change the attitudes and behavior of the client to be better in their daily lives. After the establishment of attitudes and behavior, this would affect the application of diet and daily fluid intake, hence the maximum impact to the decline of IDWG.

Counseling with the posters according to the theory of Lawrence Green in [10] can change the behavior of a person's health behavioral factors (behavior causes). One of problems faced by patients with CKD is less knowledge of IDGW. Green in 1990 said that efforts to increase knowledge is to provide health education. Health education can be done through the counseling using poster media to improve the behavior of patients with CKD to control IDGW.

\section{METHODS}

This research is quasi-experimental. The population in this study were all clients who undergo regular hemodialysis therapy two times a week at Hemodialysis Unit PHC Surabaya hospital in December 2016. The number of population was 125 people. Sampling used in this study was a non-probability sampling. After sorting through the inclusion and exclusion criteria, the overall number of respondents for this study were 30 people and of all the samples do not have clients to drop out.

The independent variable in this study is the fluid intake counseling with poster media. The dependent variable in this study is Interdialytic Weight Gain (IDWG). Pre-test data and post-test taken by the observation sheet. The data were analyzed with statistical test. Paired T-Test to determine the difference between before and after treatment in each group as well as using Independent T-Test to determine the difference between the treatment group and the control group, The degree of significance in this test is $\alpha \leq 0.05$.

\section{RESULTS}

Table 1 described about the distribution of the respondents in treatment group and control group.In both group the distribution were equal. The majority respondents were at the age of $>40->60$ yeas old, experienced hemodialysis $>1-<3$ times a year, had senior high school on the level of education, self employee, and had salary $>3-<5$ million Indonesian Rupiah.

TABLE 1. THE CHARACTERISTICS OF RESPONDENTS

\begin{tabular}{|c|c|c|c|c|}
\hline \multirow{2}{*}{ Characteristics } & \multicolumn{2}{|c|}{ Treatment } & \multicolumn{2}{|c|}{ Control } \\
\hline & $\mathrm{F}$ & $(\%)$ & $\mathrm{F}$ & $(\%)$ \\
\hline \multicolumn{5}{|l|}{ Age (years) } \\
\hline$<20$ & 0 & $0,0 \%$ & 0 & $0,0 \%$ \\
\hline$<20-<40$ & 3 & $20,0 \%$ & 4 & $26,7 \%$ \\
\hline$<40->60$ & 9 & $60,0 \%$ & 9 & $60,0 \%$ \\
\hline$>60$ & 3 & $20,0 \%$ & 2 & $13,3 \%$ \\
\hline \multicolumn{5}{|c|}{ Hemodyalisis time (years) } \\
\hline$<1$ & 2 & $13,3 \%$ & 2 & $13,3 \%$ \\
\hline$>1-<3$ & 8 & $53,3 \%$ & 7 & $46,7 \%$ \\
\hline$>3-<5$ & 4 & $26,7 \%$ & 4 & $26,7 \%$ \\
\hline$>5$ & 1 & $6,7 \%$ & 2 & $13,3 \%$ \\
\hline \multicolumn{5}{|l|}{ Education } \\
\hline Elementary & 0 & $0,0 \%$ & 1 & $6,7 \%$ \\
\hline Junior & 2 & $13,3 \%$ & 3 & $20,0 \%$ \\
\hline Senior & 9 & $60,0 \%$ & 8 & $53,3 \%$ \\
\hline University & 4 & $26,7 \%$ & 3 & $20 \%$ \\
\hline \multicolumn{5}{|l|}{ Job } \\
\hline Seller & 2 & $13,3 \%$ & 1 & $6,7 \%$ \\
\hline Enterpreneur & 7 & $46,7 \%$ & 5 & $33,3 \%$ \\
\hline Employee & 3 & $20,0 \%$ & 5 & $33,3 \%$ \\
\hline Others & 3 & $20,0 \%$ & 4 & $26,7 \%$ \\
\hline \multicolumn{5}{|l|}{ Salary } \\
\hline Not fixed & 2 & $13,3 \%$ & 1 & $6,7 \%$ \\
\hline <1 Million Rp. & 0 & $0,0 \%$ & 1 & $6,7 \%$ \\
\hline$>1-<3$ Million Rp. & 3 & $20,0 \%$ & 4 & $26,7 \%$ \\
\hline$>3-<5$ Million Rp. & 7 & $46,7 \%$ & 8 & $53,3 \%$ \\
\hline >5 Million Ro. & 3 & $20,0 \%$ & 1 & $6,7 \%$ \\
\hline
\end{tabular}


TABLE 2. THE IDWG LEVEL OF RESPONDENTS

\begin{tabular}{|c|c|c|c|c|c|c|}
\hline \multirow[t]{2}{*}{ No } & \multicolumn{3}{|c|}{ Treatment } & \multicolumn{3}{|c|}{ Control } \\
\hline & Pre & Post & $\Delta$ & Pre & Post & $\Delta$ \\
\hline 1 & 3,5 & 3 & 0,5 & 3 & 3 & 0 \\
\hline 2 & 4 & 3 & 1 & 3,5 & 3,5 & 0 \\
\hline 3 & 4 & 3 & 1 & 4 & 4 & 0 \\
\hline 4 & 3 & 2 & 1 & 3 & 3,5 & $>0,5$ \\
\hline 5 & 3 & 2,5 & 0,5 & 3 & 3 & 0 \\
\hline 6 & 4 & 3,5 & 0,5 & 3,5 & 3,5 & 0 \\
\hline 7 & 3,5 & 2,5 & 1 & 3 & 2,5 & $<0,5$ \\
\hline 8 & 4 & 3 & 1 & 3,5 & 3,5 & 0 \\
\hline 9 & 4 & 3,5 & 0,5 & 4 & 4 & 0 \\
\hline 10 & 3 & 2,5 & 0,5 & 4 & 5 & $>1$ \\
\hline 11 & 4 & 4 & 0 & 3 & 3,5 & $>0,5$ \\
\hline 12 & 3,5 & 2 & 1,5 & 3 & 3 & 0 \\
\hline 13 & 4 & 3 & 1 & 3,5 & 3,5 & 0 \\
\hline 14 & 3 & 3 & 0 & 4 & 4 & 0 \\
\hline \multirow[t]{5}{*}{15} & 4 & 2,5 & 1,5 & 4 & 4,5 & $>0,5$ \\
\hline & \multicolumn{2}{|c|}{ Mean } & & \multicolumn{2}{|c|}{ Mean } & \\
\hline & 3.36 & 2,86 & & 3,46 & 3,6 & \\
\hline & \multicolumn{3}{|c|}{$\begin{array}{l}\text { Paired T-test } \\
0,000\end{array}$} & \multicolumn{3}{|c|}{$\begin{array}{c}\text { Paired T-test } \\
0,164\end{array}$} \\
\hline & \multicolumn{6}{|c|}{$\begin{array}{c}\text { Independent T test } \\
0,002\end{array}$} \\
\hline
\end{tabular}

Table 2 showed that there were differences IDWG between treatment and control group. The mean of pre-test result on treatment group was 3.36 and the post test result was 2.86 . It indicates that there was a decreasing value on IDWG on treatment group. However in the control group the mean of pretest result was 3.46 and then slightly decrease on the post test result become 3.6. Although the value of IDWG were decreased both in treatment and control group, but the independent t-test result statistically show that there was a significant differences between the post-test result in treatment group compare to control group.

\section{DISCUSSION}

IDWG is usually fairly constant for every patient and is influenced by nutritional factors, environmental factors, and self-care levels. The increase in the interdialytic end period, as well as the variation in the IDWG values in different periods indicate an increase in IDWG. IDWG is considered a measure of adherence of patients undergoing hemodialysis therapy. Several authors found an association between IDWG and hemodialysis nutritional status, patient blood pressure, clinical implications, as well as midterm and long-term prognostic values [11].

Statistical analysis shows that health education with counseling using poster media has more significant effect on IDWG compared with media leaflets. This is because the poster has a larger size and can be installed in strategic places. Poster is a two-dimensional visual media that contains pictures and short messages. Posters are not only important to convey a particular message but can also motivate the behavior of someone who sees it.

The quality of life of patients undergoing hemodialysis has decreased in the physical domain, social relations, environment, comfort, energy, positive feelings, mobility, daily living activities, work capacity, personal relationships, sexual activity, and transportation [12]. Research conducted by [13], in $97 \mathrm{CKD}$ patients undergoing hemodialysis, showed a decrease in the quality of life in aspects of limited vitality, physical function, and physical role. They also reported much lower physical function and lower mental health scores.

The results showed that the majority of patients with CKD who underwent hemodialysis in the treatment and control group were age range $>40->60$ years. In addition, age is also a variable that is inversely proportional to IDWG. Younger patients usually have a greater appetite, along with greater intake of sodium and water. The results of this study are not in accordance with the behavior theory of [14], which states that age is one of the factors that influence the behavior of a person.

This study revealed that the average of CKD patient is over 40 years old. The United States Renal Data System (USRDS) states that the incidence is highest at the age of 60 years. The aging process can affect the changes in kidney function [15], whereas [7] revealed that although $41 \%$ of patients with CKD are more experienced at age over 40 years. This is also consistent with research conducted by [16], which states that the average age of respondents with chronic renal failure who underwent hemodialysis who adhere to fluid intake compliance between 40-50 years.

Based on the duration of hemodialysis, it was found that the respondents in the treatment and control group had similarities in undergoing hemodialysis for $>1-<3$ years. According to a study conducted by [9], states that the majority of hemodialysis patients are at intervals 1-5 year, with a percentage of $41.3 \%$. CKD sufferers who undergo hemodialysis will feel very thirsty due to angiotensin II, the circulating hormone that interacts in the limbic structure of the brain that can cause thirst. Disposal of fluids during hemodialysis may cause a decrease in circulating volume of the body, and may further stimulate the formation of angiotensin II in patients who complain of excessive thirst during dialysis [17].

IDWG decline can be caused by increased knowledge and motivation of patients after being given counseling using posters and supported by educational background of respondents who mostly have medium and high education. Herzberg's theory sees that there are two factors that drive one's motivation: the intrinsic factor that arises from within each person, and the extrinsic factors that come from outside of one's self. Counseling about fluid intake is an outside driver of ourselves that can increase people's motivation to maintain IDWG.

The results of this study support the health behavior theory which states that the health of a person or society is influenced by two main factors, namely behavioral factors and external environmental factors. The Precede-Proceed model focuses on the study of human behavior problems and the factors that influence them, and how to improve the health behavior by trying to change, maintain or improve behavior in a more positive direction. In the model there is an early stage of the process is to review or assessment (precede) of behavior, and at the end of the stage is to follow up (proceed) which aims to improve health [10]. [14], declared that knowledge is one of the predisposing factors that influence a person's behavior. Knowledge or cognitive domain is very important in shaping a 
person's actions [18]. The most respondents in this study had high school educational background which is expected to receive information properly. However, [19], stating that education does not affect behavioral change, it depends on the availability of resources obtained that individual. Health officers have a very important role to changes patient's behavior by providing clear information in the form of health education. However this is not in accordance with what is stated by [20], that patients who have a higher education will have a broader knowledge which allows the patient able to control himself in overcoming the problems, having high confidence, experienced, and have precise estimates of how to overcome the incident. It is easy to understand what is recommended by health officials, and can reduce the anxiety that can assist individuals in making decisions. Knowledge or cognitive domain is essential for the formation of action. Behavior-based knowledge will be more lasting than those which doesn't [8]. Education is an integral part of the development. The educational process can not be separated from the development process itself. Directed development and aims to develop qualified human resources and the development of economic sectors, with each other and mutually take place simultaneously.

The amount of income also affects one's behavior in utilizing health facilities. Low income will be related to the use of health care and its prevention. Someone who does not take advantage of existing health services may be because they do not have enough money to buy drugs or pay for transportation [21]. Individuals who have affluent socioeconomic status will be able to supply all the facilities needed to meet their needs. Conversely, individuals with low socioeconomic status will have difficulty meeting their needs. The results showed that the highest income owned by the respondents in the treatment group or the control group that is the highest income ranged between $>3-<5$ million.

Patients who undergo hemodialysis often experience failure in maintaining the diet, one cause is the patient's inability to control the consumption of salt. Salt is the cause of increased thirst, increasing the desire to consume fluids [22]. This is a challenge for health professionals, especially nurses to prevent IDWG increases. Counseling is given to hemodialysis patients who can improve the quality of life of patients with chronic renal failure that can be a model in caring for CKD patients.

One of the duties of the nurse is to provide health education to the patient. Counseling to patients can help patients cope with the increase in IDWG, especially in fluid restriction and food preservation, which helps nurses to know how many thirst-infected hemodialysis patients and how to optimize nursing care to prevent it [22]. The increase in IDWG in hemodialysis patients is one cause of death in patients with CKD. Another study showed that of 110 patients who were counseled about fluid intake restriction, $72 \%$ of these patients showed a decrease in IDWG [23]. The data show that patients with CKD experience discouragement so that they are potentially not adhering to fluid intake restriction therapy, causing an increase in IDWG [24]. Such patients need counseling and nursing education to optimize their standard of living, take care of themselves and prevent complications.
Although in this study, there is a decline in the value of IDWG, but has not reached the normal range (0.9 to $1.3 \mathrm{~kg})$. This can be due to the provision of counseling about fluid intake with less optimal poster media. It should provide different materials tailored to the level of understanding of respondents. It may also be influenced by other factors that influence uncontrolled IDWG improvement in this study, such as patient and family factors, and psychosocial factors including fluid intake, thirst, social support, self efficacy, and stress. The counseling process in patients undergoing hemodialysis should be performed for six visits, if it is considered necessary, may be added. The ideal time for consultation is 30-60 minutes The counseling process provided has functions such as prevention function, adaptation function, repair function and development function of health problem experienced. With fluid intake counseling, patients are expected to determine, determine, apply and adhere to daily fluid intake restrictions.

\section{CONCLUSION AND RECOMMENDATION}

Counseling of fluid intake in patients undergoing hemodialysis with a poster media is effective in improving patient awareness in preventing IDWG increase. Although this study is only conducted on one hemodialysis unit in a hospital, it can be recommended for nurses to provide nursing care to patients undergoing hemodialysis to prevent IDWG increase, which is expected to improve the quality of life of CKD patients

\section{REFERENCES}

[1] S. C. Smeltzer and B. G. Bare, Buku Ajar Keperawatan Medikal. Jakarta: EGC, 2006.

[2] S. A. Price and L. M. . Wilson, Patofisiologi: Konsep Klinis Proses-Proses Penyakit Volume 2, 6th ed. Jakarta: EGC, 2006.

[3] Badan Penelitian dan Pengembangan Kesehatan Kementrian Kesehatan RI, "Riset Kesehatan Dasar (Riskesdas 2008)," Jakarta, 2008.

[4] K. Denhaerynck, D. Manhaeve, F. Dobbels, D. Garzoni, C. Nolte, and S. De Geest, "Prevalence and consequences of nonadherence to hemodialysis regimens.," Am. J. Crit. Care, vol. 16, no. 3, p. 222 35; quiz 236, May 2007.

[5] Maria Elena Tovazi and Valentina Mazzoni, "Personal Paths of Fluid Restriction In Patients on Hemodialysis," Nephrol. Nurs. J., vol. 39, no. 3, pp. 207-215, 2012.

[6] C. Kugler, H. Vlaminck, A. Haverich, and B. Maes, "Nonadherence With Diet and Fluid Restrictions Among Adults Having Hemodialysis," J. Nurs. Scholarsh., vol. 37, no. 1, pp. 25-29, Mar. 2005.

[7] A. S. Levey et al., "National Kidney Foundation Practice Guidelines for Chronic Kidney Disease: Evaluation, Classification, and Stratification," Ann. Intern. Med., vol. 139, no. 2, p. 137, Jul. 2003.

[8] Notoatmodjo, Promosi Kesehatan dan Ilmu Perilaku. Jakarta: Rineka Cipta, 2007.

[9] K. Alharbi and E. B. Enrione, "Malnutrition is 
prevalent among hemodialysis patients in Jeddah, Saudi Arabia," Saudi J. Kidney Dis. Transplant., vol. 23, no. 3, pp. 598-608, 2012.

[10] Nursalam, Metodologi Penelitian Ilmu Keperawatan. Jakarta: Salemba Medika, 2013.

[11] F. M. van der Sande, J. P. Kooman, W. H. van Kuijk, and K. M. Leunissen, "Management of hypotension in dialysis patients: role of dialysate temperature control.," Saudi J. Kidney Dis. Transpl., vol. 12, no. 3, pp. 382-386, 2001.

[12] P. Theofilou, "Quality of Life in Patients Undergoing Hemodialysis or Peritoneal Dialysis Treatment," $J$. Clin. Med. Res., vol. 3, no. 3, pp. 132-138, May 2011.

[13] J. Cleary and J. Drennan, "Quality of life of patients on haemodialysis for end-stage renal disease," J. Adv. Nurs., vol. 51, no. 6, pp. 577-586, Sep. 2005.

[14] Green, L. W. and M. W. Kreuter, Health Promotion Planning: An Educational and Ecological Approach, 4th ed. New York: McGraw-Hill, 2005.

[15] A. C. Schoolwerth et al., "Chronic kidney disease: a public health problem that needs a public health action plan.," Prev. Chronic Dis., vol. 3, no. 2, p. A57, Apr. 2006.

[16] S. Baraz, S. Parvardeh, E. Mohammadi, and B. Broumand, "Dietary and fluid compliance: an educational intervention for patients having haemodialysis," J. Adv. Nurs., vol. 66, no. 1, pp. 6068, Jan. 2010.
[17] G. Graziani et al., "Abnormal hemodynamics and elevated angiotensin II plasma levels in polydipsic patients on regular hemodialysis treatment," Kidney Int., vol. 44, no. 1, pp. 107-114, Jul. 1993.

[18] D. R. Krathwohl, "A Revision of Bloom's Taxonomy: An Overview," Theory Pract., vol. 41, no. 4, pp. 212218, Nov. 2002.

[19] A. Bandura, "Social cognitive theory of selfregulation," Organ. Behav. Hum. Decis. Process., vol. 50, no. 2, pp. 248-287, Dec. 1991.

[20] Yulianti, Penerapan Model Pembelajaran Berbasis Masalah. Jakarta: Prestasi Pustaka, 2009.

[21] S. Notoatmodjo, Metodologi Penelitian Kesehatan. Jakarta: Rineka Cipta, 2010.

[22] P. Mistien, "Thirst, interdialytic weight gain, and thirst-interventions in hemodialysis patients: A literature review," Nephrol. Nurs. J., vol. 28, no. 6, pp. 601-604, 2001.

[23] H. Raza et al., "The effect of active nutritional counseling in improving biochemical nutritional parameters and fluid overload problems in maintenance hemodialysis patients.," Saudi J. Kidney Dis. Transpl., vol. 15, no. 2, pp. 140-3, 2004.

[24] U. Feroze, D. Martin, A. Reina-Patton, K. KalantarZadeh, and J. D. Kopple, "Dialysis Mental Health, Depression, and Anxiety in Patients on Maintenance Dialysis," Iran. J. Kidney Dis. IJKD, vol. 44, no. 3, pp. 173-80, 2010. 